THURSDAY, JULY 28, 1898.

\section{SUBMARINE TELEGRAPHS}

Submarine Telegraphs. By Charles Bright, F.R.S.E. Pp. 744. (London: Crosby Lockwood and Son, 1898.)

IF experience, the possession of records, filial devotion, 1 and many friendships qualify a man to chronicle contemporaneous events, Mr. Charles Bright is eminently prepared to write a history in which his father played an important part. This book is full of information. It gives evidence of great industry. It is well printed, admirably illustrated, thoroughly indexed, and makes a book of reference which should be in every engineer's library. The literature of the subject has been very meagre. Two or three text-books deal with the construction and working of cables. Many valuable papers are scattered in the Proceedings of engineering institutions, but there is no complete history of an industry that has not yet attained its jubilee. Mr. Bright has fulfilled his task very well. There is a remarkable free use of the footnote system. Sometimes the footnote, the result of subsequent inquiry, contradicts the text, but more often it gives details useful to the engineer, but uninteresting to the general reader. The book is divided into three parts : history, construction, and working. In the first part the evolution of the system of submarine telegraphy, still in active progress and without any sign of finality ahead, is lightly sketched. The days of secrecy have ceased ; and manufacturers, engineers, and commercial managers are equally ready to publish all they know. The rough and tumble rule of thumb method of the speculative pioneer has disappeared, and the results of practical observation and scientific deduction control the progress of the industry. It is very interesting to note that the form of the first effective cable laid from Dover to Calais in $185 \mathrm{I}$ has been but very little departed from, but its details and dimensions have changed with every requirement and for every ocean. Its development has given a knowledge of the sea, of its botton, of its currents, and of its life, that has enlightened the geographer and the biologist. Science has advanced pari passu with engineering. The engineer has succeeded in interring many a foolish assumption in Davy Jones' locker, and in bringing to light and illustrating many a new condition undreamt of by the mathematician. Mr. Bright points out that success was obtained in face of scientific and public opinion. Even the Astronomer Royal of the day (Airy)

"had very foolishly stated that it would be impossible to deposit the cable at so great a depth; and that in any case it was mathematically out of the question to transmit electrical signals through such a length (p. $5 \mathrm{I}$ ).

Now depth is no impedinjent; there are twelve cables spanning the North Atlantic. Fifty words a minute can be sent across the ordinary Atlantic in each direction at the same time, and it is pronounced by Mr. Preece even not impossible to speak by telephone between New York NO. I 500 , VOL. 58 ] and London. The mileage of cable laid about the world is 170,000 , and $50,000,000 \mathrm{l}$. has been invested in the industry. The author avoids the prevalent mistake of using the term "knot" as a standard of length. It is a velocity, and the proper term for lengths is nautical miles (N.M.) or " nauts."

It should be recorded that the first money subscribed for the construction and laying of a submarine cable to cross the Channel, or indeed any sea, was 50ol. each from Mr. (afterwards Sir Charles) Fox, Mr. Francis Edwards, Mr. J. W. Brett, and Mr. Charles J. Wollaston-the last-named being still living. These formed "The English Channel Submarine Telegraph Comp any" in I 850 , and were the financial pioneers of the industry.

The construction, laying, and repairing of cables are very fully illustrated, the portion dealing with insulating materials is instructive, and the methods of working, together with the speed of signalling, are gone into very thoroughly. There is a want of agreement among ex perts in adopting some standard of reference as regards rate of working. Words per minute is very vague. What is the length of a word? Is it five letters, seven letters, or even ten letters per word? Are abbreviations used or not? Are the words ordinary or code? How many elements are there allowed in a letter, and how much is allowed for spacing? What allowance is made for skill? The only true criterion of speed is the number of complete waves that can be automatically and clearly transmitted per unit of time, and even this will depend on the sensitiveness and reliability of the apparatus used at each end.

Mr. Bright has executed his task in an impartial and disinterested way. He has marshalled his facts with much clearness, and the few errors detected are errors of proof-reading, easily remedied in the next edition. The most notable omission is that of the modern improvements in repairing apparatus. There is no description of cutting grapnels, or of the ingenious automatic signalling of the cable caught on the prongs of the grapnel at the bottom of the ocean. Moreover, he has not chronicled events in their chronological order, which becomes occasionally embarrassing in tracing historical sequence.

The history of submarine telegraphy is an excellent example of bold commercial enterprise, combined with blind faith in the prowess of the engineer and determined perseverance in overcoming great difficulties. The names of Cyrus Field and John Pender must always be associated with those of Bright, Canning, Varley, Kelvin, Clark, Siemens, and others, living and dead, who have done so much to establish the industry on a sound practical and commercial basis. Science, too, has benefited largely in numerous ways by this very progress. Physics, geography, biology and astronomy have each gained new facts and new conditions. The accurate determination of the longitudes of distant centres is no mean advantage: that of Madras has recently been measured with great skill. The columns of the Times every morning skow how completely space has been annihilated, and how the uttermost ends of the earth are now virtually in London. 